\title{
Interrogating the Effects of Hydrogen on the Behavior of Planar Deformation Bands in Austenitic Stainless Steel
}

\author{
J.E.C. SABISCH, J.D. SUGAR, J. RONEVICH, C. SAN MARCHI, and D.L. MEDLIN
}

The effects of internal hydrogen on the deformation microstructures of 304L austenitic stainless steel have been characterized using electron backscattered diffraction (EBSD), transmission Kikuchi diffraction (TKD), high-resolution scanning transmission electron microscopy (HRSTEM), and nanoprobe diffraction. Samples, both thermally precharged with hydrogen and without thermal precharging, were subjected to tensile deformation of 5 and 20 pct true strain followed by multiple microscopic interrogations. Internal hydrogen produced widespread stacking faults within the as-forged initially unstrained material. While planar deformation bands developed with tensile strain in both the hydrogen-precharged and non-precharged material, the character of these bands changed with the presence of internal hydrogen. As shown by nanobeam diffraction and HRSTEM observations, in the absence of internal hydrogen, the bands were predominantly composed of twins, whereas for samples deformed in the presence of internal hydrogen, $\varepsilon$-martensite became more pronounced and the density of deformation bands increased. For the 20 pct strain condition, $\alpha^{\prime}$-martensite was observed at the intersection of $\varepsilon$-martensite bands in hydrogen-precharged samples, whereas in non-precharged samples $\alpha^{\prime}$-martensite was only observed along grain boundaries. We hypothesize that the increased prevalence of $\alpha^{\prime}$-martensite is a secondary effect of increased $\varepsilon$-martensite and deformation band density due to internal hydrogen and is not a signature of internal hydrogen itself.

https://doi.org/10.1007/s11661-021-06170-3

(c) This is a U.S. government work and not under copyright protection in the U.S.; foreign copyright protection may apply 2021

\section{INTRODUCTION}

PLANAR deformation bands are often observed in the microstructures of deformed austenitic stainless steels. ${ }^{[1-6]}$ It is important to understand the formation and arrangements of these microstructural features as the heterogeneous localization of deformation can negatively impact critical mechanical properties including ductility, fatigue resistance, and fracture toughness. ${ }^{[5-7]}$ Deformation bands are often dominated by planar dislocation slip, but in some systems, deformation structures can also be tied to shear-coupled crystallographic transformations. Perhaps the most fundamental of these transformations is deformation twinning. ${ }^{[8,9]}$ Additional transformations are observed in austenitic stainless steels, such as the shear-induced transformation to hexagonal closed packed (HCP)

J.E.C. SABISCH is with the Sandia National Laboratories, Livermore, CA 94551 and also with the University of Oklahoma, 770 Van Vleet Oval, Norman OK, 73019. Contact e-mail: jsabisch@ou.edu D. SUGAR, J. RONEVICH, C. SAN MARCHI, and D.L. MEDLIN are with the Sandia National Laboratories.

Manuscript submitted August 13, 2020; accepted January 28, 2021.

Article published online February 27, 2021 $\varepsilon$-martensite. ${ }^{[9-16]}$ The interplay of strain and local atomic shuffling in these bands can also drive more complex processes, a notable example being the nucleation and growth of the $\alpha^{\prime}$-martensite phase at the intersection of multiple deformation bands. ${ }^{[17-20]}$

The formation and impact of deformation bands has been reported to be sensitive to hydrogen exposure ${ }^{[4,5,21]}$ which is important since austenitic stainless steels are widely employed in diverse, safety-critical applications for high-pressure hydrogen storage and delivery. ${ }^{[22,23]}$ The notions that hydrogen may affect the interactions between dislocations, ${ }^{[23,24]}$ may increase the localization of plasticity (often referred to as hydrogen enhanced localized plasticity ${ }^{[4,21]}$, or may reduce stacking fault energy (SFE), thereby increasing slip planarity, ${ }^{[3]}$ are mechanisms commonly invoked when discussing austenitic stainless steels. Microstructural investigations have implicated the increased localization of deformation in hydrogen-precharged austenitic stainless steel as a source of local stress concentration and concomitant initiation of damage, such as microvoid and vacancy nucleation and microcracking. ${ }^{[6,25,26]}$

The hydrogen-induced formation of $\varepsilon$ - and $\alpha^{\prime}$-martensite has been widely investigated for the case of electrochemically precharged austenitic stainless 
steels. ${ }^{[27-33]}$ A challenge with such studies is that the complex initial microstructural development during electrochemical precharging makes interpretation of the underlying mechanisms and connection to the behavior of thermally precharged material difficult. In particular, electrochemically precharged specimens exhibit steep gradients of hydrogen concentration and concomitant lattice strain in the near surface regions as a result of hydrogen's high surface fugacity and low bulk diffusivity under typical electrochemical charging conditions and this internal strain can induce martensitic phase transitions. ${ }^{[30-32,34]}$ Despite these complications, observations have shown that subsequent deformation, following electrochemical precharging, can drive increased formation of $\varepsilon$-martensite. ${ }^{[35,36]}$

In contrast to studies on electrochemically charged material, only a small number of investigations have considered the strain-induced formation of $\varepsilon^{-}$and $\alpha^{\prime}$-martensite in high-pressure thermally precharged specimens. High-pressure thermal precharging is advantageous since it avoids the complexities due to the steep concentration and strain gradients associated with electrochemical charging. XRD measurements by Narita et al., showed small signatures of $\varepsilon$-martensite following thermal precharging 304 and 310 stainless steel with high-pressure hydrogen. ${ }^{[30]}$ San Marchi et al. ${ }^{[37,38]}$ reported TEM observations of $\varepsilon$-martensite formation in hydrogen-precharged $316 \mathrm{~L}$ and $304 \mathrm{~L}$ following tensile straining at $223 \mathrm{~K}$ and suggested hydrogen may favor formation of $\varepsilon$-martensite relative to mechanical twinning. Hatano et al. ${ }^{[25]}$ also observed increased strain localization, characterized by twinning and $\varepsilon$-martensite formation in a tensile deformation study of H-precharged 316 and 304 stainless steels.

In this paper, we investigate the influence of hydrogen on the development of planar deformation bands. We focus on forged $304 \mathrm{~L}$ stainless steel, comparing the evolution of the deformation microstructure with tensile strain for both hydrogen-precharged material and non-precharged material. The specific 304L stainless steel that we investigate in this paper is from the same composition and forging lot as the subject of a previous study on hydrogen-assisted crack-growth. ${ }^{[6]}$ That study found a significant reduction in fracture toughness of the hydrogen-precharged material. Furthermore, based on post-mortem scanning electron microscopy (SEM) and EBSD observations of the heavily strained regions below the fracture surfaces, the previous study proposed that damage, in the form of microvoids and microcracks, initiates at the intersection of planar deformation bands with grain boundaries and other deformation bands. These bands contained extensive $\alpha^{\prime}$-martensite in the material precharged with internal hydrogen. Here, we investigate the initial development of deformation bands at comparatively lower strains to identify the deformation structures that lead to crack nucleation and growth. As we discuss, our atomic- and nanoscale observations show strikingly different behavior between the hydrogen-precharged and non-precharged material, unresolvable in previous studies using SEM and EBSD techniques. These observations provide insight for a more thorough understanding of the initiation and evolution of deformation bands that precede fracture as well as their role in the transformation to $\alpha^{\prime}$-martensite.

\section{EXPERIMENTAL PROCEDURE}

The tensile samples used in this study were extracted from forged 304L stainless steel. The alloy composition, which conforms with the definition of $304 \mathrm{~L},{ }^{[39]}$ is shown in Table I and the yield strength is approximately 436 $\mathrm{MPa} .{ }^{[6]}$ Additional details of this alloy, its mechanical properties, and its processing (using high energy rate forging) have been discussed previously. ${ }^{[6]}$ Stress-strain curves for the tensile samples investigated in this study are provided in Supplementary Fig. S-1 (refer to electronic supplementary material).

The samples were hydrogen-precharged (HC) at a temperature of $300{ }^{\circ} \mathrm{C}$ in gaseous hydrogen at a pressure of $138 \mathrm{MPa}(20 \mathrm{ksi})$ for two weeks. These conditions allow hydrogen diffusion to generate a uniform hydrogen concentration of approximately $140 \mathrm{wppm}$ through the thickness of the samples $(4 \mathrm{~mm}$ diameter tensile coupons), as per the methods detailed by San Marchi et al. ${ }^{[26]}$ After hydrogen precharging, the tensile coupons were stored at $-55^{\circ} \mathrm{C}$ to retain the hydrogen within the material. Tensile testing was conducted within 30 to 120 minutes of removal from the freezer. Tensile samples were strained to 0,5 , and $20 \mathrm{pct}$ (true strain) in the non-charged (NC) and HC condition. An additional, non-charged (and not strained), sample was annealed at $300{ }^{\circ} \mathrm{C}$ in air for 2 weeks to evaluate the influence of the thermal history on the microstructure of the as-forged condition in the absence of pressurized hydrogen.

For the TEM investigation, $3 \mathrm{~mm}$ diameter disks were cut from the gauge section of the tensile specimens perpendicular to the tensile axis. The TEM specimens were mechanically thinned with progressively finer $\mathrm{SiC}$ sandpaper, ending with 2400 grit, to a thickness of 150 microns and then jet-polished using a solution of $10 \mathrm{pct}$ perchloric acid and 90 pct ethanol at a temperature of $12{ }^{\circ} \mathrm{C}$, potential of $24.1 \mathrm{~V}$, and current of $61 \mathrm{~mA}$ for approximately 2.5 minutes until sample perforation. This electropolishing temperature lies safely above the temperature range for which nucleation of martensite has been observed as an artifact in previous TEM electropolishing studies. ${ }^{[12,40,41]}$ For this specific alloy, temperatures below $-160{ }^{\circ} \mathrm{C}$ are required to nucleate martensite. ${ }^{[42,43]}$ Because TEM specimens are extremely thin, we do not expect any hydrogen to be retained in the electron transparent regions of the specimens. For instance, based on the diffusivity of hydrogen in $304 \mathrm{~L},{ }^{[26]}$ we compute that reduction of the hydrogen concentration to negligible concentrations would occur within less than a minute at room temperature for a thin TEM foil of typical $\sim 100 \mathrm{~nm}$ thickness.

Transmission electron microscopy (TEM) observations were conducted using a ThermoFisher Scientific Themis Z instrument operated at $300 \mathrm{kV}$ in STEM mode with probe correction. Data collection was performed in 
Table I. Nominal Composition of the 304L Stainless Steel Used in This Study (All Values in Wt Pet). ${ }^{[6]}$

\begin{tabular}{lcccccccc}
\hline $\mathrm{Fe}$ & $\mathrm{Cr}$ & $\mathrm{Ni}$ & $\mathrm{Mn}$ & $\mathrm{Si}$ & $\mathrm{C}$ & $\mathrm{N}$ & $\mathrm{P}$ & $\mathrm{S}$ \\
\hline Bal. & 19.64 & 10.6 & 1.62 & 0.65 & 0.028 & 0.04 & 0.02 & 0.0042 \\
\hline
\end{tabular}

different modes of STEM operation: High Angle Annular Dark Field (HAADF) STEM, Diffraction Contrast-STEM (DC-STEM), and scanning microprobe diffraction. DC-STEM, which is sensitive to strain contrast, ${ }^{[44,45]}$ was employed for characterizing the coarser-scale deformation microstructure. We varied the convergence angle of the STEM probe to optimize the DC-STEM for different microstructural details. We employed a $\sim 3 \mathrm{mrad}$ convergence angle for imaging the dislocations and overall deformation microstructure. We used $\mathrm{a} \sim 0.21 \mathrm{mrad}$ convergence angle to achieve $\mathrm{a}$ near-parallel probe condition for nanodiffraction measurements using a roughly $3 \mathrm{~nm}$ diameter probe.

Electron backscatter diffraction (EBSD) and transmission Kikuchi diffraction (TKD) were performed both on a ThermoFisher Helios Nanolab 660 using an Oxford Nordlys Max 2 EBSD detector and ThermoFisher Apreo LoVac C using a Bruker e-Flash FS detector with an Optimus TKD detector head. The scan step size was set to $120 \mathrm{~nm}$ for the large view-area EBSD data collection, with TKD using variable step sizes down to $20 \mathrm{~nm}$. Sample preparation for the EBSD measurements was performed using standard metallographic polishing techniques for stainless steel. The TKD measurements were conducted on the TEM specimens prepared as discussed above.

\section{RESULTS}

\section{A. As-Forged Microstructure (0 Pct Strain)}

Figure 1 shows DC-STEM observations comparing the initial (as-forged) microstructures of both the HC and NC conditions. In both cases, the initial microstructures consist of dense arrangements of dislocations that have organized into extensive cell blocks spanning multiple microns across the grains. Extended stacking faults are observed in the $\mathrm{HC}$ material, but these faults are largely absent from the NC samples. Several of these faults in the $\mathrm{HC}$ condition are presented in Figure 1(d)); higher magnification images are also provided in Supplementary Fig. S-2. Companion images of the $\mathrm{NC}$ material (thermally treated at $300{ }^{\circ} \mathrm{C}$ in air to mimic the thermal precharging conditions) are also presented in Figure 1; comparison of the true as-forged condition and the air-heated condition is provided in Supplementary Fig. S-3. The $300{ }^{\circ} \mathrm{C}$ thermal treatment (in the absence of hydrogen) shows no appreciable change from the microstructure of the as-forged material, with no observation of extended stacking faults.

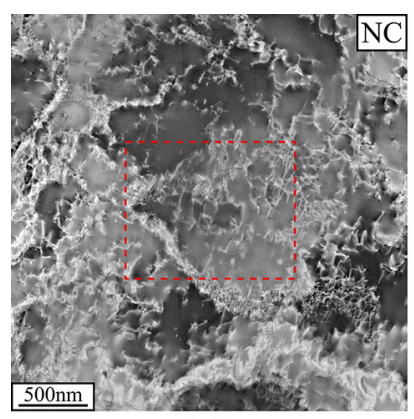

(a)

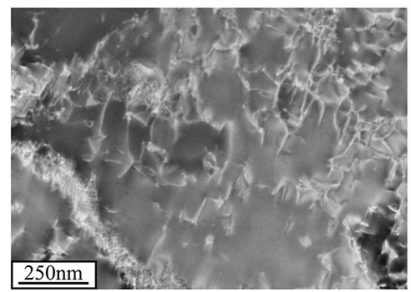

(c)

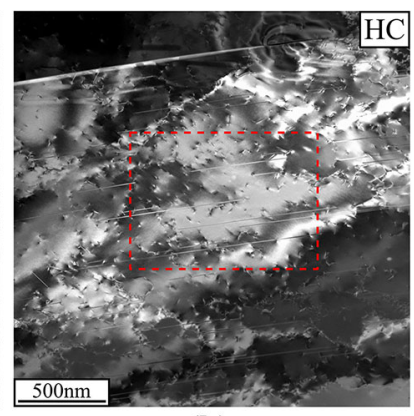

(b)

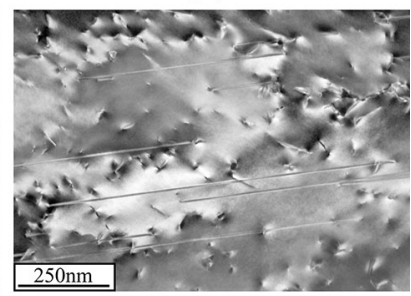

(d)
Fig. 1-DC-STEM images showing the initial microstructure of the as-forged non-charged sample $(a, c)$ and 140 wppm hydrogen-precharged sample $(b, d)$, both of which were exposed to $300{ }^{\circ} \mathrm{C}$ for 2 weeks. The areas marked in red boxes within $(a, b)$ are shown in higher magnification in $c, d$. Both microstructures have similar arrangements of dislocation networks some of which have formed into cell blocks. Extended stacking faults are observed in the HC specimen (d), but not in the NC specimen. A higher magnification image of the faults in $d$ is provided in Supplementary Fig. S-2.

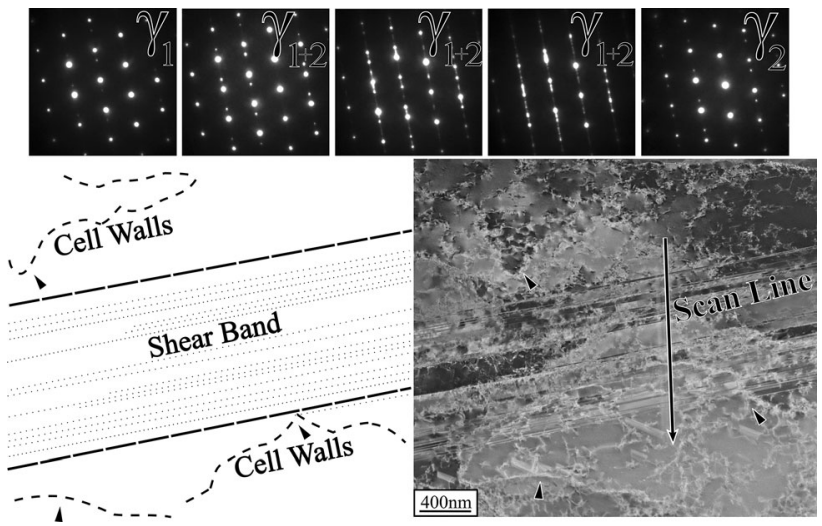

Fig. 2-DC-STEM image, defect structure diagram, and nanobeam diffraction patterns collected from a deformation band in the 5 pct strained NC specimen. Nanobeam diffraction patterns (Top) show several patterns collected in sequence across the deformation band along the path indicated by the arrow. Deformation twinning is observed, whereas strain-induced $\varepsilon$-martensite is absent.

\section{B. 5 Pct Strain Condition}

The microstructures of the strained material, for both the $\mathrm{NC}$ and $\mathrm{HC}$ samples, contain planar deformation bands and other planar features, such as loosely aligned nanotwins, that increase in density with strain. For both sample conditions, the deformation bands lie parallel with $\{111\}$, planes in the austenite phase. Figures 2 and 3 show examples of these deformation bands for the 5 pct strained $\mathrm{NC}$ and $\mathrm{HC}$ specimens, respectively. In 
both cases, the analyzed grain was oriented along a $[110]_{\gamma}$ zone axis since this orientation places the $\{111\}_{\gamma}$ planes of the deformation bands into an edge-on orientation. Atomic resolution HAADF-STEM images showing representative images of the deformation bands for the two cases are shown in Figure 4.

The deformation microstructures change significantly when the material is deformed in the presence of internal hydrogen. For the NC material deformed to 5 pct strain, the diffraction and HRSTEM measurements detected only deformation twins. Outside of a few heavily faulted regions along the twin/matrix boundaries, no secondary $\varepsilon$-martensite is observed within the 5 pct strained NC samples. We note that the diffraction patterns obtained from the deformation bands are typically streaked in the direction normal to the $\{111\}$, planes. This is a result of the high density of interfaces lying parallel to $\{111\}_{\gamma}$. In contrast, in the hydrogen-precharged material we
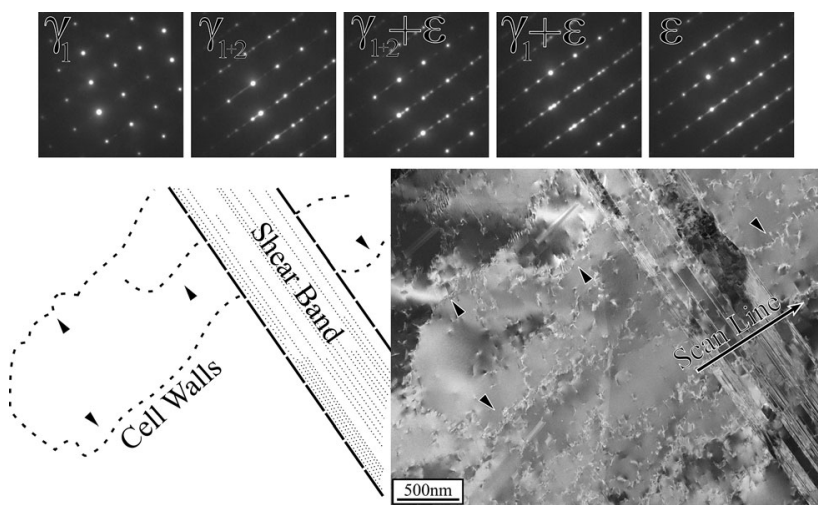

Fig. 3-DC-STEM, defect structure diagram, and nanobeam diffraction patterns collected from a deformation band in the $5 \mathrm{pct}$ strained HC sample. In contrast to the NC sample shown in Fig. 2, the deformation band contains both deformation twins and $\varepsilon$-martensite. The position of the diffraction scan line is indicated. Positions of several dislocation cell walls are indicated by the small black triangles.
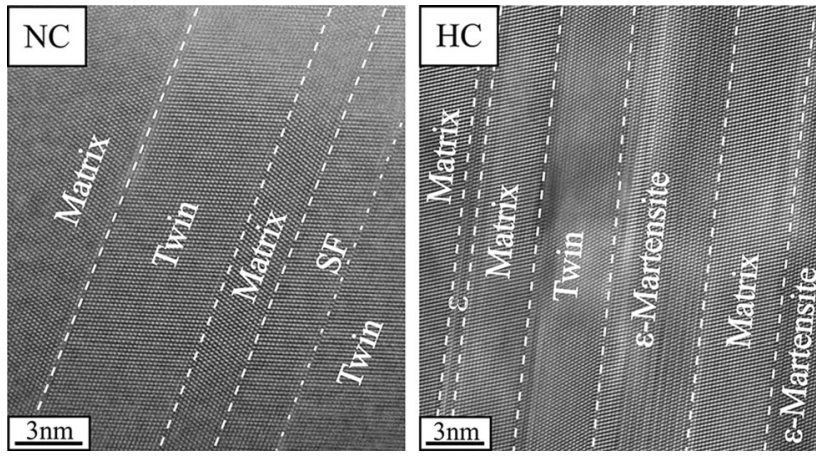

Fig. 4-High-resolution STEM images of the 5 pct strained samples showing the internal structure of deformation bands in the $\mathrm{NC}$ and $\mathrm{HC}$ specimens. In the $\mathrm{NC}$ case, the deformation band is dominated by twinning with some stacking faults also present. In contrast, in the HC case HRSTEM also shows extensive formation of $\varepsilon$-martensite. Both samples show the internal deformation band structure contains multiple nanometer thin laths requiring HRSTEM to resolve. observed extensive formation of $\varepsilon$-martensite in addition to twinning. We did not observe isolated dissociated dislocations as in the initial microstructure and hypothesize that under strain these have further extended and have been incorporated into the arrays of stacking faults constituting the laths of $\varepsilon$-martensite. From the analysis of the electron diffraction patterns we find that the $\varepsilon$-martensite is oriented in the Burger orientation relationship (OR). This orientation aligns the close-packed planes and directions in the two phases, i.e., $\{111\}_{\gamma} \mid\{0001\}_{\varepsilon}$ and $110_{\gamma} \mid\langle 11 \overline{2} 0\rangle_{\varepsilon}{ }^{[46]}$ The lattice constants inferred from the measured d-spacings in the patterns $\quad\left(a_{\gamma}=3.50 \AA, a_{\alpha}=2.85 \AA, c_{\alpha}=2.95 \AA, \quad\right.$ and $a_{\varepsilon}=2.45 \AA, c_{\varepsilon}=4.10 \AA$ ) are consistent with literature values for the phases. ${ }^{[13,16,47]}$ We did not observe $\alpha^{\prime}$-martensite at any of the deformation bands in either the 5 pct strained $\mathrm{NC}$ or $\mathrm{HC}$ conditions.

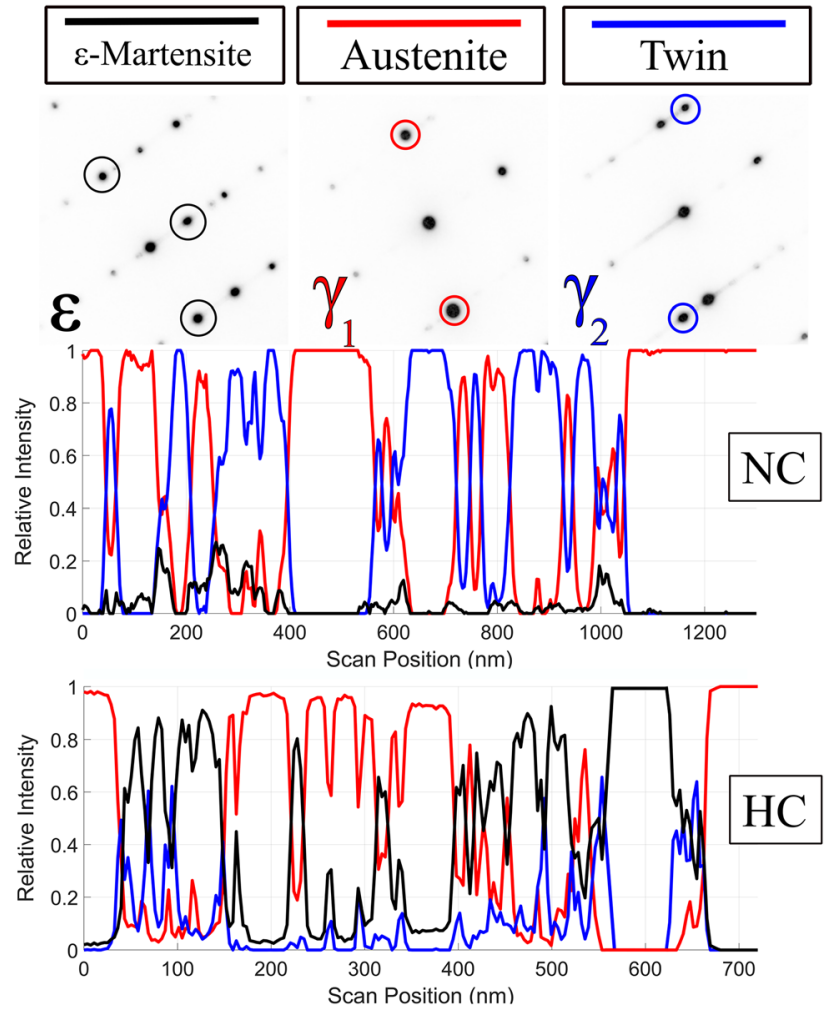

Fig. 5-Quantitative analysis of the 5 pct strain nanobeam diffraction line scans across the shear bands. Diffraction spot position used to distinguish between $\varepsilon$-martensite and austenite in the matrix $\left(\gamma_{1}\right)$ and twin $\left(\gamma_{2}\right)$ orientations with color coding located above the inverted contrast diffraction patterns. The two plots show the relative intensity, directly correlating to volume fraction of each phase, of the 5 pct strained NC sample (top graph taken from scan position in Fig. 2, sampled an interval of $3.25 \mathrm{~nm}$ ) and of the $5 \mathrm{pct}$ HC samples (bottom graph taken from scan position in Fig. 3, sampled at an interval of $3.6 \mathrm{~nm}$ ). Twinning is the dominant deformation mode for the $\mathrm{NC}$ sample, whereas $\varepsilon$-martensite dominates within the shear band of the HC sample. In both cases, the thicknesses of the twin and martensite plates are generally on the order of tens of nanometers or less. Note that the weak signal indexed as $\varepsilon$-martensite in the $\mathrm{NC}$ sample is due to diffraction streaking normal to the close-packed planes from the closely spaced interfaces. 
To characterize the relative amounts of twins and martensite within the deformation bands, we analyzed diffraction pattern line scans by plotting the relative intensity of reflections specific to the $\gamma$-matrix, $\gamma$-twin orientations and the $\varepsilon$-martensite phase. Figure 5 shows the plots corresponding to the scan positions marked in Figures 2 and 3 for the 5 pct strained $\mathrm{NC}$ and $\mathrm{HC}$ conditions, respectively.

The diffraction line scans further illustrate the marked difference in the resulting deformation microstructure between the $\mathrm{NC}$ and $\mathrm{HC}$ conditions. In the $\mathrm{NC}$ condition, the deformation bands exhibit copious twinning, whereas in the $\mathrm{HC}$ condition the deformation is dominated by the formation of $\varepsilon$-martensite. In both cases, the thicknesses of the individual matrix, twin, and/or $\varepsilon$-martensite lamellae within the deformation bands are tens of nanometers or less. For the 5 pct strained HC samples, the bands contained approximately 60 pct $\varepsilon$-martensite phase fraction (based on measurements of 7 deformation bands scanned across 6 grains). In the 5 pct strained NC samples, nine different deformation bands in three different grains were scanned. In these, only one band showed evidence of fully transformed $\varepsilon$-martensite, and this was over only 6 pct of the total scan line within the large-scale scan used to survey for $\varepsilon$-martensite.

\section{20 Pct Strain Condition}

The final coarse-scale microstructures after 20 pct strain are significantly different in the $\mathrm{NC}$ and $\mathrm{HC}$ conditions. These microstructures are presented in Figure 6, which shows large area EBSD scans ((IPF) orientation maps and image quality (IQ) maps) of the 20 pet strained samples for both $\mathrm{NC}$ and $\mathrm{HC}$ conditions. In the HC sample, extensive planar deformation bands cross entire grains and grain boundaries. The planar deformation features correspond to regions within the
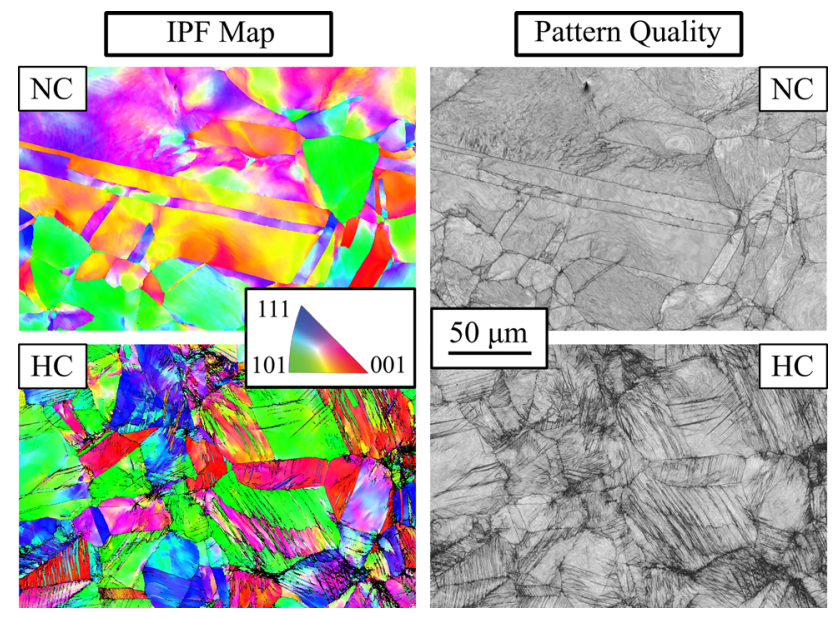

Fig. 6 - Comparison between HC and NC samples using EBSD for the 20 pct strain samples. Pattern quality images (right) show large-scale development of planar features internal to the grains within HC samples suggesting more localized strain. This corresponds to the IPF map (left) within the NC samples having large misorientation gradients within the grains while lacking the characteristic unindexable bands seen in the $\mathrm{HC}$ sample. phase map where $\varepsilon$-martensite and $\alpha^{\prime}$-martensite can be observed (or pixels cannot be indexed). In comparison, planar deformation bands are not apparent in the $\mathrm{NC}$ samples (strained $20 \mathrm{pct}$ ) at the length scale shown in Figure 6.

Figure 7 shows representative TKD micrographs, phase maps from TKD, and DC-STEM images of the microstructures of the $\mathrm{HC}$ and $\mathrm{NC}$ conditions strained to 20 pct. The microstructures observed at 20 pct strain have developed significantly from the isolated deformation bands observed in TEM at 5 pet strain to intersecting bands at 20 pct strain. In the TKD IPF maps of Figure 7, the NC and HC TEM specimens showed various arrangements of intersecting planar deformation bands with a significantly higher deformation band density in the HC specimen. The TKD phase maps show that while $\varepsilon$ - and $\alpha^{\prime}$-martensite are observed within the deformation bands of the HC specimen, they are not readily indexed within the $\mathrm{NC}$ specimen, as the deformation bands are too thin. The internal color gradients in the $\mathrm{NC}$ specimen is evidence of diffuse
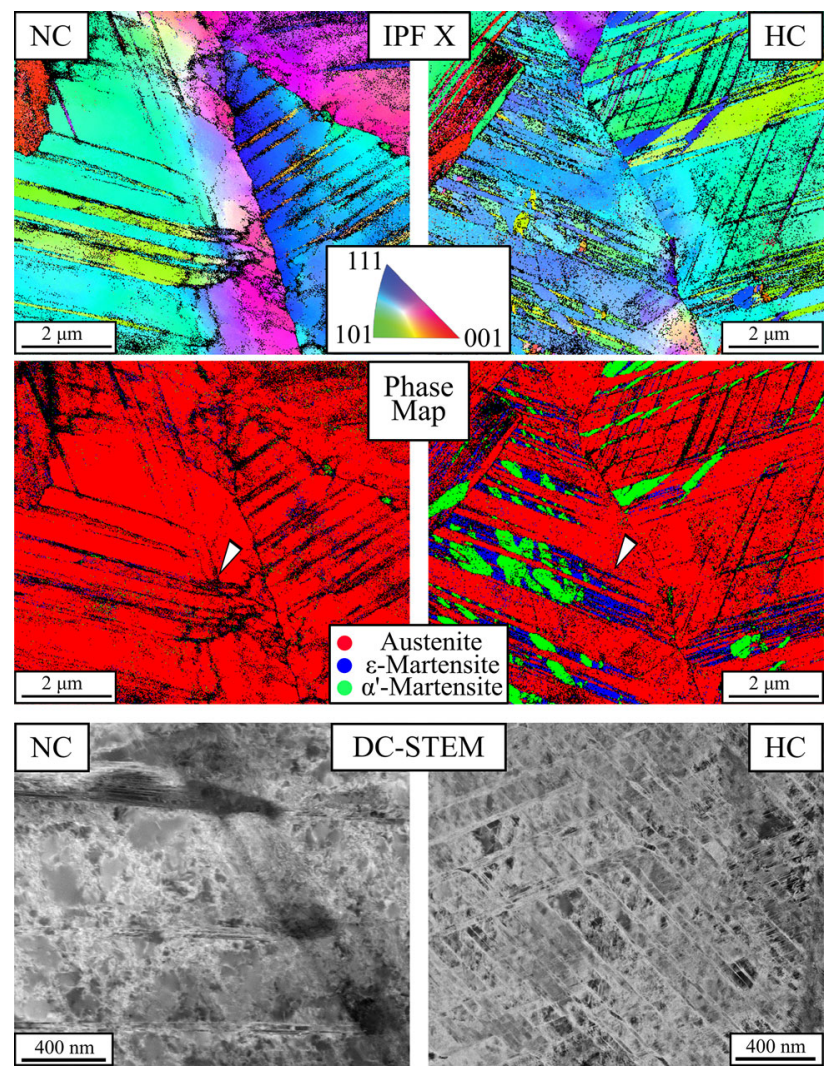

Fig. 7-Comparison between HC and NC TEM specimens as seen through TKD IPF map (top), phase map (middle) and DC-STEM (bottom). TKD overview scans show a large difference in deformation band density and phase content between $\mathrm{HC}$ and $\mathrm{NC}$ conditions. Orientation and grain boundary influences were observed in the formation of auxiliary phases and deformation bands. A small amount of $\alpha^{\prime}$-martensite was observed along grain boundaries in the $\mathrm{NC}$ specimen. Deformation bands in NC samples were too fine to be indexed reliably in TKD, while $\mathrm{HC}$ deformation bands showed $\alpha^{\prime}$-martensite interlaced with $\varepsilon$-martensite. Planar features seen in the TEM for the NC specimen consist of twins with the HC specimen containing $\varepsilon$-martensite laths that form $\alpha^{\prime}$-martensite at lath intersections. 
deformation (gradients in misorientation); in contrast, deformation appears to be concentrated in discrete deformation bands in the HC specimen (with comparatively modest misorientation (color) gradients within a grain). The most common deformation band morphology observed after 20 pet strain, for both the $\mathrm{HC}$ and $\mathrm{NC}$ cases, is the development of intersecting deformation bands, indicative of two active $\{111\}_{\gamma}$ shear systems.

The fine deformation band structures of the 20 pct strained specimens are considered in greater detail in Figures 8 (NC) and $9(\mathrm{HC})$. Figure 8 shows an intersection of several planar features (marked by the white triangle) with a deformation band of dislocations (black triangle). As with the 5 pct strained NC condition, the 20 pet strained NC condition shows twinning with little $\varepsilon$-martensite, which we observe only as a few atomic planes of stacking disorder in the vicinity of twin boundaries (see Supplementary Fig. S-4). Furthermore, while there exists some $\alpha^{\prime}$-martensite at grain boundaries (e.g., see Figure 7) within the 20 pct strained $\mathrm{NC}$ specimen, we find no evidence of $\alpha^{\prime}$-martensite when taking nanobeam diffraction measurements across or along planar deformation bands. We also observe some streaking in the patterns, which may be indicative of fine-scale twinning or stacking faults.

The observations are very different for the $\mathrm{HC}$ condition. Figure 9 shows a DC-STEM image and nanobeam diffraction patterns from one of the crosshatched regions for the 20 pct strained $\mathrm{HC}$ condition. An HRSTEM image illustrating an example of an $\alpha^{\prime}$-nuclei observed at an intersection of shear bands within the same grain is shown in Figure 10. In the 20 pct strained HC condition, the presence of both $\varepsilon$ and $\alpha^{\prime}$-martensite is observed in diffraction measurements across the primary deformation band. As with the 5 pct strained sample, the $\varepsilon$-martensite is crystallographically aligned in the Burgers orientation relationship. The
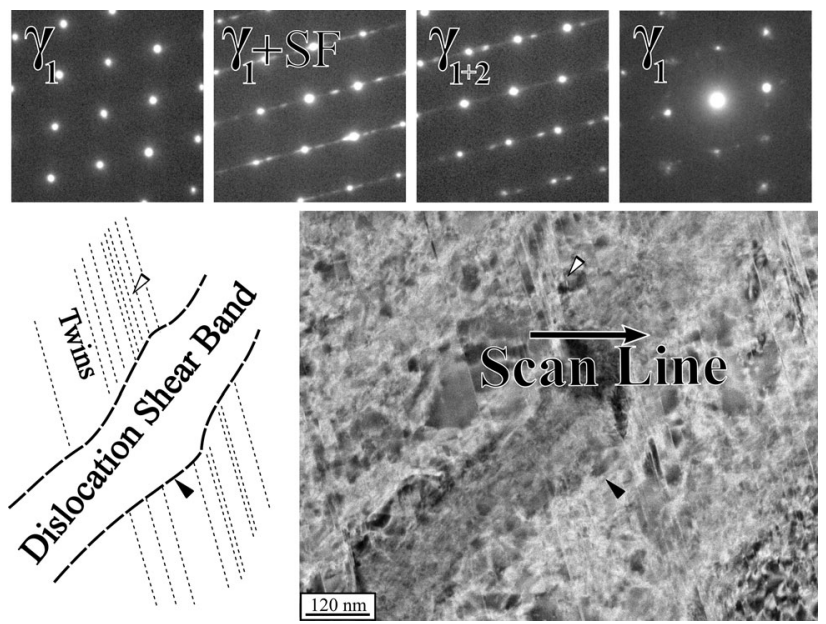

Fig. 8-Diffraction patterns (Top), deformation diagram (bottom left) and DC-STEM image (bottom right) of a region containing high stacking fault activity and twinning interacting with a dislocation shear band (NC, 20 pct strain). Twins are active within the region marked by the white triangle, with a dislocation shear band marked by the black triangle. $\alpha^{\prime}$-martensite is aligned relative to the matrix in a manner consistent with the Kurdjumov-Sachs (KS) relationship, namely $\{111\}_{\gamma} \mid\{011\}_{\alpha^{\prime}}$ and $\langle 110\rangle_{\gamma} \mid 111_{\alpha^{\prime}}$ with the close-packed planes and directions remaining parallel after the crystal transforms. The $\alpha^{\prime}$-martensite nuclei are elongated along the $\varepsilon$-martensite-laden deformation bands, with only small regions expanding into the austenitic matrix. The deformation bands along which the $\varepsilon$-martensite is preferentially consumed to form $\alpha^{\prime}$-martensite is known as the primary shear band. This convention is taken as the $\varepsilon$-martensite in the primary shear band planes is more densely packed and
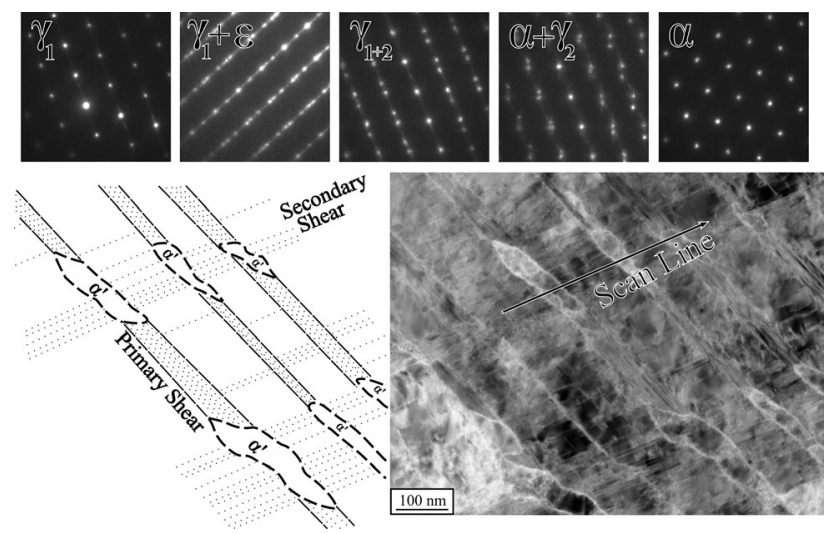

Fig. 9-Higher magnification image of DC-STEM for the HC specimen in Fig. 8 (20 pct strain) showing the intersections of two $\{111\}$, shear directions (diffraction scan line marked with arrow). The initial diffraction patterns show the transition from pure austenite with minimal streaking to $\varepsilon$-martensite and austenite twins. With the introduction of secondary shearing the border between austenite and $\alpha^{\prime}$-martensite becomes visible finally transforming into pure $\alpha^{\prime}$-martensite.

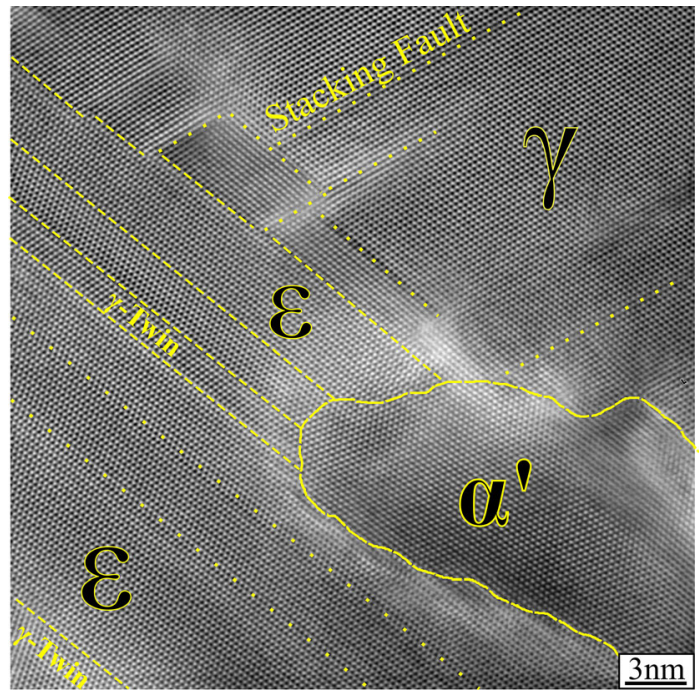

Fig. 10-HAADF-STEM image of HC 20 pct strained material showing $\alpha^{\prime}$-martensite nucleus at intersection of deformation bands. While the $\alpha^{\prime}$-martensite nucleus extends outside of the $\varepsilon$-martensite into the austenite, $\varepsilon$-martensite is preferentially consumed over austenite to form the $\alpha^{\prime}$-martensite nucleus. 
the austenite is more fully converted to $\varepsilon$-martensite than along the secondary shear direction of Figure 9.

\section{DISCUSSION}

The observations presented here, summarized in Table II, show that internal hydrogen strongly influences the development and local structure of deformation bands in forged 304L stainless steel. First, the density of deformation bands increases significantly with internal hydrogen, in contrast to the NC condition, which is characterized by larger gradients in local misorientation and lower density of deformation bands. In addition, internal hydrogen promotes the development of $\varepsilon$-martensite within the deformation bands. Second, as straining progresses, $\alpha^{\prime}$-martensite more easily nucleates within the hydrogen-precharged material, preferentially forming at the intersections of $\varepsilon$-martensite-laden bands. The $\alpha^{\prime}$-martensite nuclei grow elongated along the $\varepsilon$-martensite laths, generally remaining within the deformation bands. In the absence of internal hydrogen, the deformation bands are dominated by deformation twinning and have only negligible quantities of $\varepsilon$-martensite, with $\alpha^{\prime}$-martensite observed at grain boundary intersections but not at deformation band intersections. We consider the significance of these observations in greater detail in the next sections.

\section{A. Formation of E-Martensite Within Deformation Bands}

In FCC materials such as austenite, glide of $\frac{1}{6}\langle 112\rangle$ dislocations mediates both deformation twinning and the shear-induced transformation to the HCP structure (such as $\varepsilon$-martensite). ${ }^{[9,48,49]}$ The difference between these structural outcomes is related to the $\frac{1}{6}\langle 112\rangle$ dislocations and the faults that they produce in the structure. Specifically, a deformation twin is produced by the successive glide of $\frac{1}{6}\langle 112\rangle$ dislocations on adjacent $\{111\}$ planes, reversing the stacking from $\mathrm{ABCABC}$ to CBACBA at the twin plane. ${ }^{[8,9]}$ In contrast, the FCC $\rightarrow$ HCP transformation occurs by glide of $\frac{1}{6}\langle 112\rangle$ dislocations on every second $\{111\}$ plane, changing the $\mathrm{ABCABC}$ stacking to ABABAB type stacking, a transformation that is structurally equivalent to introducing stacking fault on every other plane. ${ }^{[8,9]}$

Although the nucleation mechanisms for such twinning and shear transformation continues to be a question of research focus, ${ }^{[9,50-53]}$ it seems clear that factors promoting either an energetic or kinetic preference for stacking fault formation will also promote $\varepsilon$-martensite over twinning as response to shear stress. Thus, our observations showing the formation of extended stacking faults in the as-precharged microstructure, combined with the observed formation of $\varepsilon$-martensite at planar deformation bands upon deformation of the $\mathrm{HC}$ material suggests a mechanistic link between the effect of internal hydrogen, the prevalence of stacking faults within the microstructure, and the observed preference for strain-induced $\varepsilon$-martensite over deformation twinning. 
It is widely thought that hydrogen reduces the stacking fault energy of austenitic stainless steels. Indeed, observations of $\varepsilon$-martensite in cathodically charged austenitic stainless steels provided key early evidence for such a hydrogen-induced reduction of SFE, ${ }^{[27,28]}$ although as noted above, the interpretation of these results is complicated due to the high surface strains imparted by the cathodic charging. As many have noted, such strains may themselves drive the martensitic transformations in the near surface regions of cathodically charged material. ${ }^{[28,30,32,34,54]}$ Unfortunately, there are only a few studies for which experimentally measured values of the influence of hydrogen on SFE in the austenitic stainless steels have been reported, either directly, by in situ and ex situ TEM $^{[27,55-57]}$ or indirectly by X-ray diffraction. ${ }^{[54]}$ These reports suggest hydrogen-induced reduction of stacking fault energy of at most 14 to 50 pet.

Taken on its own, such a reduction of SFE seems insufficient to explain the necessarily wide dissociation of lattice dislocations into extended faults required to produce bands of $\varepsilon$-martensite. For instance, based on experimental SFE measurements for non-charged 304L stainless steel, one would expect the equilibrium width of stacking fault ribbons at dissociated lattice dislocations to fall within the range of 5 to $24 \mathrm{~nm} \cdot{ }^{[58-62]}$ Since the stacking fault width is inversely proportional to SFE, even a 50 pct reduction in SFE due to hydrogen would at most give an equilibrium fault width of $48 \mathrm{~nm}$.

However, this simple interpretation neglects the response of a dislocation to loading conditions. As Byun et al., have discussed and modeled, ${ }^{[63]}$ because the leading and trailing partial dislocations in a dissociated lattice dislocation possess different Burgers vectors, the partial dislocations, will in general, experience different Peach-Koehler forces under load. As a result, above a critical shear stress, the leading partial can break away leaving an extended stacking fault that is bounded only by the distance to a blocking obstacle, such as a grain boundary. The critical stress for the fault divergence falls with decreasing stacking fault energy. Drawing on Byun's model, Talonen and Hänninen ${ }^{[7]}$ evaluated the formation of shear bands containing $\varepsilon$ - and $\alpha$ '-martensite in several metastable austenitic stainless steels of differing stacking fault energy, concluding that the model predicted well the critical stresses required for shear band formation by stacking fault divergence.

This notion of stacking fault divergence under load has been further developed by considering the barriers for the nucleation of martensite and deformation twin nuclei ${ }^{[53,64]}$ which are also sensitive to stacking fault energy. ${ }^{[20]}$ The theoretical development by GalindoNava et al. ${ }^{[53]}$ predicts a progressive change of the deformation microstructure and phase distribution as the stacking fault energy is reduced. For materials with high SFE, the deformation occurs through lattice dislocation slip, but in materials with low SFE there is an increased predominance of deformation twinning, followed by $\varepsilon$-martensite, and eventually $\alpha$-martensite. The transitions between these deformation modes are fairly narrow and very sensitive to SFE and loading conditions. Based on this framework, it seems reasonable to anticipate that even small SFE reductions due to the presence of hydrogen may be sufficient to drive a transition from deformation twinning to shear-banding dominated by $\varepsilon$-martensite.

\section{B. $\alpha$-Martensite Forming Within $\varepsilon$-Martensite Laths}

Regardless of the underlying mechanism by which hydrogen promotes $\varepsilon$-martensite, the resulting $\varepsilon$-martensite does influence the subsequent development of $\alpha^{\prime}$-martensite with further straining. In particular, deformation band intersections, particularly those dominated by $\varepsilon$-martensite, are known to serve as effective nucleation sites for $\alpha^{\prime}$-martensite. This $\mathrm{HCP} \rightarrow \mathrm{BCC}$ (or BCT) transformation behavior has also been observed previously in a variety of austenitic steels and has been thoroughly examined by Olson and Cohen. ${ }^{[17-20]}$ Within the Olson-Cohen model, an intersection between a lath of $\varepsilon$-martensite and a lath of "faulted" $\varepsilon$-martensite, provides the proper atomic arrangement for nucleation of $\alpha^{\prime}$-martensite, with a secondary shear provided by $\frac{1}{6}\langle 112\rangle$ dislocations distributed one to every three $\{111\}$ planes. Prior observations of $\alpha^{\prime}$-martensite nucleation at $\varepsilon$-martensite intersections for a variety of hydrogen-free systems, ${ }^{[7,11,18,65-67]}$ as well as the observations presented here, are consistent with the preferential nucleation of $\alpha^{\prime}$-martensite at such intersections. Molecular Dynamics simulations by Sinclair and Hoagland ${ }^{[68]}$ further support the Olson-Cohen mechanism, with the caveat that the generally observed KS orientation relationship, the same one observed in the HC specimen, is not observed in the MD simulations, likely as a result of the high levels of strain required for $\alpha^{\prime}$-martensite to form.

These previous observations are relevant in considering our results since the $\alpha^{\prime}$-martensite is most readily observed under conditions where $\varepsilon$-martensite laths are well developed, as in the HC material with 20 pet strain. Previous magnetic measurements on the same material by San Marchi et al., detected more than 1 pct $\alpha^{\prime}$-martensite in the absence of hydrogen only after 20 pct tensile strain at room temperature. ${ }^{[69]}$ The lack of $\varepsilon$-martensite laths intersecting other $\varepsilon$-martensite laths in $\mathrm{NC}$ material at 20 pct strain explains the absence of $\alpha^{\prime}$-martensite in the NC samples; greater strain is required to generate these $\varepsilon$-martensite intersections and induce the $\alpha^{\prime}$-martensite transformation (based on ferritoscope measurements). ${ }^{[69]}$ Our observations, which link internal hydrogen to the enhanced formation of densely packed $\varepsilon$-martensite laths, suggest that the $\alpha^{\prime}$-martensite formation is thus a secondary effect of the hydrogen-induced deformation structures and not a direct result of internal hydrogen.

It is important to note that increased formation of $\alpha^{\prime}$-martensite in the presence of hydrogen cannot be inferred for all austenitic stainless steels. For instance, Macadre et al. observed a reduction of strain-induced $\alpha^{\prime}$-martensite with hydrogen (introduced through thermal precharging) for a metastable $\mathrm{Fe}-16 \mathrm{Cr}-10 \mathrm{Ni}$ alloy, despite observations of increased localized shear. ${ }^{[70,71]}$ This result indicates that although shear localization is a clear effect of hydrogen in stainless steels, increased 
$\alpha^{\prime}$-martensite formation is not always the result of deformation in the presence of hydrogen and requires a fundamental change in the deformation behavior to occur. Similarly, magnetic measurements on these materials when deformed at low temperature also suggest a reduction in the amount of $\alpha^{\prime}$-martensite transformation, which is attributed to the accommodation of the deformation structures (and presumably the required intersections) when the volume fraction of $\alpha^{\prime}$-martensite transformation exceeds about 20 pct. ${ }^{[69]}$ It is also important to note that hydrogen-induced shear localization (and $\varepsilon$-martensite) ${ }^{[72]}$ can also arise in stable austenitic stainless steels, such as $21 \mathrm{Cr}-6 \mathrm{Ni}-9 \mathrm{Mn}$, that do not form $\alpha^{\prime}$-martensite phases and yet still suffer from hydrogen embrittlement. ${ }^{[73-75]}$ Nevertheless, the results presented here illuminate the character of hydrogen-induced deformation structures for the important 304L alloy system and motivate future work to better understand fundamental mechanism by which hydrogen influences the formation of $\varepsilon$-martensite and the subsequent evolution of hydrogen-induced damage.

\section{CONCLUSION}

We have characterized the influence of internal hydrogen on the development of planar deformation bands and associated deformation microstructures in forged 304L austenitic stainless steel strained in uniaxial tension. We observe that the structure of these deformation bands is different with and without the presence of internal hydrogen. In the absence of internal hydrogen, deformation bands are dominated by austenite deformation twins. In contrast, in the hydrogen-precharged material, there is a higher density of deformation bands and these are largely composed of $\varepsilon$-martensite.

Hydrogen also affects the subsequent formation of strain-induced $\alpha^{\prime}$-martensite at higher strains, although this effect may be indirect. Specifically, if $\alpha^{\prime}$-martensite nucleation occurs preferentially at $\varepsilon$-martensite intersections, as is consistent with our observations, then the increased tendency for strain-induced $\varepsilon$-martensite formation with internal hydrogen will drive a correlated increase in $\alpha^{\prime}$-martensite formation, at least for the initial, nucleation stage. Additionally, our observations that $\varepsilon$-martensite laths are partially transformed to $\alpha^{\prime}$-martensite at higher strains, suggests that this preferential association of $\alpha^{\prime}$ - with $\varepsilon$-martensite continues beyond the initial nucleation stage, as the $\varepsilon$-martensite is consumed to grow $\alpha^{\prime}$-martensite.

These observations raise an intriguing question: how, mechanistically, does internal hydrogen enhance the initial formation of $\varepsilon$-martensite? Our observation of extended stacking faults in the as-forged, hydrogen-precharged material suggests that the increased formation of strain-induced $\varepsilon$-martensite in the presence of internal hydrogen may be connected to hydrogen's influence on stacking fault formation. Future atomistic and dislocation-scale modeling to determine the influence of internal hydrogen on the energetics and kinetics of stacking fault and $\varepsilon$-martensite formation for compositions representative of austenitic stainless steel would help to answer this question.

\section{ACKNOWLEDGMENTS}

The authors thank Prof. Ryan Sills (Rutgers University) and Norm Bartelt for helpful discussions during the preparation of this manuscript and Mark Homer for assistance with much of the TEM specimen preparation. Sandia National Laboratories is a multimission laboratory managed and operated by National Technology and Engineering Solutions of Sandia, LLC, a wholly owned subsidiary of Honeywell International Inc. for the U.S. Department of Energy's National Nuclear Security Administration under contract DE-NA-0003525. This paper describes objective technical results and analysis. Any subjective views or opinions that might be expressed in the paper do not necessarily represent the views of the U.S., Department of Energy or the United States Government.

\section{OPEN ACCESS}

This article is licensed under a Creative Commons Attribution 4.0 International License, which permits use, sharing, adaptation, distribution and reproduction in any medium or format, as long as you give appropriate credit to the original author(s) and the source, provide a link to the Creative Commons licence, and indicate if changes were made. The images or other third party material in this article are included in the article's Creative Commons licence, unless indicated otherwise in a credit line to the material. If material is not included in the article's Creative Commons licence and your intended use is not permitted by statutory regulation or exceeds the permitted use, you will need to obtain permission directly from the copyright holder. To view a copy of this licence, visit http://creat ivecommons.org/licenses/by/4.0/.

\section{SUPPLEMENTARY INFORMATION}

The online version of this article (https://doi.org/10. 1007/s11661-021-06170-3) contains supplementary material, which is available to authorized users.

\section{REFERENCES}

1. V. Gerold and H. Karnthaler: Acta Metall., 1989, vol. 37, pp. 2177-83.

2. T.C. Pekin, C. Gammer, J. Ciston, C. Ophus, and A.M. Minor: Scripta Mater., 2018, vol. 146, pp. 87-90.

3. S. Barannikova, M.V. Nadezhkin, V. Mel'nichuk, and L. Zuev: TechnPhys. Lett., 2011, vol. 37, p. 793. 
4. H.K. Birnbaum and P. Sofronis: Mater. Sci. Eng., A, 1994, vol. 176, pp. 191-202.

5. D. Ulmer and C. Altstetter: Acta Metall. Mater., 1991, vol. 39, pp. $1237-48$.

6. H. Jackson, C. San Marchi, D. Balch, B. Somerday, and J. Michael: Metall. Mater. Trans. A, 2016, vol. 47A, pp. 4334-50.

7. J. Talonen and H. Hänninen: Acta Mater., 2007, vol. 55, pp. $6108-18$.

8. J.W. Christian and S. Mahajan: Prog. Mater Sci., 1995, vol. 39, pp. $1-157$.

9. S. Mahajan, M. Green, and D. Brasen: Metall. Trans. A, 1977, vol. 8, pp. 283-93.

10. P.L. Mangonon and G. Thomas: Metall. Trans., 1970, vol. 1, pp. 1577-86.

11. L. Bracke, L. Kestens, and J. Penning: Scripta Mater., 2007, vol. 57, pp. 385-88.

12. J. Dash and H. Otte: Acta Metall., 1963, vol. 11, pp. 1169-78.

13. C. Huang, G. Yang, Y. Gao, S. Wu, and S. Li: J. Mater. Res., 2007, vol. 22, pp. 724-29.

14. W. Pitsch: Philos. Mag., 1959, vol. 4, pp. 577-84.

15. Y. Shen, X. Li, X. Sun, Y. Wang, and L. Zuo: Mater. Sci. Eng., A, 2012, vol. 552, pp. 514-22.

16. X.-S. Yang, S. Sun, and T.-Y. Zhang: Acta Mater., 2015, vol. 95, pp. 264-73.

17. G. Olson and M. Cohen: J. Less Common Met., 1972, vol. 28, pp. $107-18$

18. G. Olson and M. Cohen: Metall. Trans. A, 1975, vol. 6, p. 791.

19. G. Olson and M. Cohen: Metall. Trans. A, 1976, vol. 7, pp. 1905-14.

20. G. Olson and M. Cohen: Metall. Trans. A, 1976, vol. 7, pp. 1897-1904.

21. M.L. Martin, M. Dadfarnia, A. Nagao, S. Wang, and P. Sofronis: Acta Mater., 2018, vol. 165, pp. 734-50.

22. H. Fukumoto, H. Kobayashi, S. Oshima, K. Kawamata, Pressure Vessels and Piping Conference, 2017, vol. 58004, p. V06BT06A033.

23. Y. Murakami: The Effect of Hydrogen on Fatigue Properties of Metals Used for Fuel Cell System, Advances in Fracture Research, Springer, New York, 2006, pp. 167-95.

24. R.B. Sills and W. Cai: Philos. Mag., 2018, vol. 98, pp. 1491-1510.

25. M. Hatano, M. Fujinami, K. Arai, H. Fujii, and M. Nagumo: Acta Mater., 2014, vol. 67, pp. 342-53.

26. C. San Marchi, B.P. Somerday, and S.L. Robinson: Int. J. Hydrogen Energy, 2007, vol. 32, pp. 100-16.

27. A. Inoue: Trans. ISIJ, 1979, vol. 19, pp. 170-78.

28. M. Holzworth and M. Louthan, Jr: Corrosion, 1968, vol. 24 , pp. 110-24.

29. D. Eliezer, D. Chakrapani, C. Altstetter, and E. Pugh: Metall. Trans. A, 1979, vol. 10, pp. 935-41.

30. N. Narita, C. Altstetter, and H. Birnbaum: Metall. Trans. A, 1982 , vol. 13 , pp. $1355-65$.

31. P. Rozenak and A. Loew: Corros. Sci., 2008, vol. 50, pp. 3021-30.

32. P. Rozenak, L. Zevin, and D. Eliezer: J. Mater. Sci., 1984, vol. 19, pp. 567-73.

33. J. Lee, C. Park, H. Park, N. Kang, Int. J. Hydrogen Energy, 2020, pp. 10227-32

34. P. Maulik and J. Burke: Scr. Metall., 1975, vol. 9, pp. 17-22.

35. J. Hermida and A. Roviglione: Scripta Mater., 1998, vol. 39 pp. $1145-49$.

36. D. An, W. Krieger, and S. Zaefferer: Int. J. Plast., 2020, vol. 126, p. 102625 .

37. C. San Marchi, K. Nibur, D. Balch, B. Somerday, X. Tang, G. Schiroky, T. Michler, Effects of Hydrogen on Materials, Proceedings of the 2008 International Hydrogen Conference (Moran WY, 2008), ASM International, Materials Park OH, 2009, pp. 88-96.

38. C. San Marchi, N. Yang, T. Headley, J. Michael, 18th European Conference on Fracture (ECF18), vol. 30. Dresden, Germany, 2010 .
39. AMS F Corrosion Heat Resistant Alloys Committee, Steel, Corrosion Resistant, Bars, Wire, Shapes, and Forgings (STABILIZED Mar 2015), AMSQQS763D, SAE International, 2015, p. 22.

40. J. Gaggero and D. Hull: Acta Metall., 1962, vol. 10, pp. 995-98. 41. H. Warlimont: Trans. Metall. Soc. AIME, 1961, vol. 221, pp. 1270-71.

42. D. Peckner, I.M. Bernstein, and D. Peckner: Handbook of Stainless Steels, McGraw-Hill, New York, 1977.

43. T. Angel: J. Iron Steel Inst., 1954, vol. 177, pp. 165-74.

44. P. Phillips, M. Brandes, M. Mills, and M. De Graef: Ultramicroscopy, 2011, vol. 111, pp. 1483-87.

45. P. Phillips, M. Mills, and M. De Graef: Philos. Mag., 2011, vol. 91, pp. 2081-2101.

46. W. Burgers: Physica, 1934, vol. 1, pp. 561-86

47. X.-S. Yang, S. Sun, X.-L. Wu, E. Ma, and T.-Y. Zhang: Sci. Rep., 2014, vol. 4, p. 6141.

48. S. Mahajan: Metall. Trans. A, 1975, vol. 6A, pp. 1877-86.

49. S. Mahajan and G. Chin: Acta Metall., 1973, vol. 21, pp. 1353-63.

50. K. Rahman, V. Vorontsov, and D. Dye: Acta Mater., 2015, vol. 89, pp. 247-57.

51. C. Cayron: Crystals, 2018, vol. 8, p. 181.

52. S. Pramanik, A.A. Gazder, A.A. Saleh, and E.V. Pereloma: Mater. Sci. Eng. A, 2018, vol. 731, pp. 506-19.

53. E.I. Galindo-Nava and P. Rivera-Díaz-del-Castillo: Acta Mater., 2017, vol. 128, pp. 120-34.

54. A.E. Pontini and J.D. Hermida: Scripta Mater., 1997, vol. 37, pp. 1831-37.

55. I. Robertson: Eng. Fract. Mech., 1999, vol. 64, pp. 649-73.

56. P. Ferreira, I.M. Robertson, and H. Birnbaum: Mater. Sci. Forum, 1996, vol. 207, pp. 93-96.

57. M. Whiteman and A. Troiano: PSSBR, 1964, vol. 7, pp. K109-K110.

58. J. Lu, L. Hultman, E. Holmström, K.H. Antonsson, M. Grehk, W. Li, L. Vitos, and A. Golpayegani: Acta Mater., 2016, vol. 111, pp. $39-46$

59. G.M. de Bellefon, M. Gussev, A. Stoica, J. van Duysen, and K. Sridharan: Scripta Mater., 2018, vol. 157, pp. 162-66.

60. G.M. de Bellefon, J. van Duysen, and K. Sridharan: J. Nucl. Mater., 2017, vol. 492, pp. 227-30.

61. Y. Petrov: Int. J. Mater. Res., 2012, vol. 103, pp. 551-53.

62. S. Yang and J. Spruiell: J. Mater. Sci., 1982, vol. 17, pp. 677-90.

63. T. Byun: Acta Mater., 2003, vol. 51, pp. 3063-71.

64. S. Pisarik and D.C. Van Aken: Metall. Mater. Trans. A, 2016, vol. 47, pp. 1009-18.

65. J. Venables: Philos. Mag., 1962, vol. 7, pp. 35-44.

66. T.-H. Lee, E. Shin, C.-S. Oh, H.-Y. Ha, and S.-J. Kim: Acta Mater., 2010, vol. 58, pp. 3173-86.

67. S. Martin, C. Ullrich, and D. Rafaja: Mater. Today, 2015, vol. 2, pp. S643-S646.

68. C. Sinclair and R. Hoagland: Acta Mater., 2008, vol. 56, pp. $4160-71$

69. C. San Marchi, J.A. Ronevich, J.E.C. Sabisch, J.D. Sugar, D.L. Medlin, B. Somerday, Int. J. Hydrogen Energy, 2020.

70. A. Macadre, N. Nakada, T. Tsuchiyama, and S. Takaki: Int. J. Hydrogen Energy, 2015, vol. 40, pp. 10697-10703.

71. A. Macadre, T. Tsuchiyama, and S. Takaki: J. Mater. Sci., 2017, vol. 52, pp. 3419-28.

72. B.P. Somerday, H.F. Jackson, C.W. San Marchi, 2011.

73. A.J. West and M.R. Louthan: Metall. Trans. A, 1982, vol. 13, pp. 2049-58.

74. Y. Chang, C. Luo, C. Chen, and S. Chen: Mater. Sci. Eng., A, 2013, vol. 577, pp. 23-28.

75. K. Nibur, B. Somerday, D. Balch, and C. San Marchi: Acta Mater., 2009, vol. 57, pp. 3795-3809.

Publisher's Note Springer Nature remains neutral with regard to jurisdictional claims in published maps and institutional affiliations. 